\title{
Folk Physics in the Twenty-first Century: Understanding Tooling as Embodied
}

\author{
Dorothy M. Fragaszy ${ }^{1, *}$ and Madhur Mangalam ${ }^{2}$ \\ ${ }^{1}$ Department of Psychology, University of Georgia, Athens \\ ${ }^{2}$ Department of Physical Therapy, Movement and Rehabilitation Science, Northeastern University \\ *Corresponding author (Email: dfragaszy@ gmail.com)
}

Citation - Fragaszy, D. M., \& Mangalam, M. (2020). Folks physics in the twenty-first century: Understanding tooling as embodied. Animal Behavior and Cognition, 7(3), $457-473 . \quad$ doi: https://doi.org/10.26451/abc.07.03.12.2020

\begin{abstract}
Povinelli's (2000) studies with chimpanzees (Pan troglodytes) reported in "Folk Physics for Apes" were firmly grounded in a Cartesian view of knowledge, which posits that humans use abstract concepts such as force, gravity, and shape to reason causally about events and plan our actions (with tools in the case of Folk Physics for Apes). Povinelli set out to examine if chimpanzees, like humans, used causal concepts to solve mechanical problems, as the Cartesian view predicts. However, Povinelli's findings uniformly challenged his expectations. Povinelli's book stimulated research and contributed to the development of alternate understandings of how animals (including humans) use tools. We summarize one alternative approach, Ecological psychology, elucidate how predictions drawn from this approach, explain (post hoc) the findings presented in Folk Physics for Apes, and suggest directions for continuing work on this topic from an Ecological approach. Ecological psychology posits direct perception and requires analysis of the animal-task-environment system, thus providing a distinct alternative to the Cartesian approach. Twenty years on, Povinelli's elegant exposition in Folk Physics for Apes of the Cartesian view of how animals use tools, and his efforts to explain the findings of his experiments in this framework, still stimulate those who study animal behavior and cognition from different theoretical perspectives.
\end{abstract}

Keywords - Ecological psychology, affordance, perception, spatial relation, Cartesian dualism

Povinelli's (2000) book Folk Physics for Apes (hereafter, FPA), with the collaboration of J. Reaux, L. Theall, and S. Giambrone, has been highly influential in the field of comparative psychology not just because of its elegant exposition, but rather because it was firmly grounded in a specific theory of knowledge (Indirect realism in the form of Cartesian dualism). It explicitly sought to demonstrate continuity in psychological processes (specifically, in causal reasoning) across apes and humans, a key notion of Darwinian evolutionary theory. However, when empirical work challenges one's theory of knowledge - as Povinelli's work challenged his — one should take notice. Povinelli certainly did - he thought carefully about his findings. At the end of the volume, he arrived at a much-altered interpretation of chimpanzees' causal reasoning, its expression in behavior, and the nature of psychological continuity across primates than he presented at the beginning. His open-minded, honest approach was (and remains) a great strength of this work.

In the same spirit of open-mindedness, we propose a very different approach to a key set of chimpanzees' behaviors tapped in Povinelli's studies, specifically those that involved manipulating objects to solve mechanical problems, including using tools. Our purpose is to show how a different epistemological approach (Direct realism) provides a different evaluation of Povinelli's findings. Aside from the historical interest of this exercise, we show that since FPA was published, Ecological 
psychology (also known as action-perception theory), which is derived from Direct realism, has led to new ways of understanding how animals solve physical problems in general, and how they use tools in particular. In the first part of this essay, we briefly situate Povinelli's experiments in relation to the predominant epistemology underpinning research in cognitive psychology in the 1990's, when the work presented in FPA was conducted, and to the evidence at that time of chimpanzees' problem-solving abilities. This allows the reader to understand Povinelli's interest in causal reasoning and his objectives for his project. In the second part, we summarize the methods and findings from the project, and Povinelli's interpretations. In the third part, we present Direct realism as an epistemological alternative to Indirect realism/Cartesian dualism, and illustrate how that epistemology, in the form of Ecological psychology, leads to a different understanding of the problems that Povinelli presented to the chimpanzees, and different understanding of their behavior as they attempted to solve the problems. We conclude by suggesting that FPA catalyzed the exploration of alternative approaches to physical cognition, and we highlight some current questions that flow from the particular alternative approach that we present.

\section{Philosophical Context and Background}

Povinelli adopted the philosophical position that dominated much of cognitive psychology in the second half of the twentieth century, which is that the mind constructs knowledge from atomistic sensory information, and that representations of the world constructed by the mind guide action (Bennett \& Hacker, 2003; Dennett \& Kinsbourne, 1992; Fodor, 1974). This philosophical stance, a version of dualism, traces back to Plato, with rich elaborations and discussions in Western philosophy over the intervening millennia, most prominently in the works of René Descartes (1989), John Locke (1998), George Berkeley (1988), and David Hume (1986) in the seventeenth century. In the philosophy of mind, dualism refers to the idea that mind and body are qualitatively different entities; one cannot be reduced to the other. Fodor (1974) and Davidson (2001) provide influential modern treatments of mind/body dualism. Although it is an oversimplification, we will refer to epistemological dualism as Cartesian dualism. Representational cognitive psychology is grounded in Cartesian dualism.

The Cartesian view requires a "cognitive interface" between the outside world and the knower, leading to the causal theory of perception. According to the causal theory of perception, perception proceeds in two stages. First, a physical stimulus (resulting from a change in the world) impacts the (passive) observer. Next, something inside the observer detects the change and infers what caused it. In this way, we experience consciously the inference, not the stimulus directly; in fact, we can never experience the "real world" directly. This view underlies Povinelli's conception of causal reasoning. Causal reasoning allows the actor-perceiver to infer a causal relation between two events, such as their own action and the movement of an object, or the movement of one object relative to that of another. Povinelli's goal was to examine chimpanzees' causal reasoning and to compare it with humans' causal reasoning in the same situations. This comparison could reveal similarities between humans' and chimpanzees' understanding of the physical world. Povinelli adopts the shorthand phrase "folk physics" to refer to humans' causal understanding of physical entities and processes evident in our everyday interactions with the physical world, including our use of hand tools.

\section{Chimpanzees' Problem-Solving Behavior}

In Chapter 3 of FPA, Povinelli reviews chimpanzees' actions with objects in the context of manufacturing and using tools. Here he accurately recounts Köhler's (1927) observations of his chimpanzees' behavior when presented with problems involving moving objects of various shapes, such as stacking boxes or wielding sticks, to achieve a goal. In contrast to the typical presentation of these studies in the literature as revealing 'insight' via quick solutions, Köhler found the chimpanzees to be particularly inefficient and their behavior highly variable. For example, Sultan, when first encountering a banana fixed out of reach above his head, and one box in the enclosure, at first tried to reach the banana 
directly by jumping. Eventually, however, after moving the box around the room in an undirected fashion, he moved it underneath the banana and stood on it to reach the banana. He did this again a second day. Two days after that, the banana was fixed to a higher ceiling in a different room, and two boxes and two sticks were provided. Köhler (1927, pp. 45-47) described in detail Sultan's vigorous but ultimately unsuccessful efforts to reach the banana with both boxes and sticks. Sultan did not manage to bring two boxes together below the banana despite carrying them and moving them all around the cage. Other chimpanzees behaved in a similar manner; none of them stacked two boxes efficiently in a manner suggesting 'insight.' Köhler concluded (1927, pp. 149-150) that chimpanzees perceive gravity and visual forms in space very differently than do humans. Chimpanzees do not "set one box on top of the other" to reach the banana, as humans do. "For all structures that we know (and are familiar with optically) are achieved by the apes by chance at best, and as it were, by the "struggle for not wobbling"" (Köhler, 1927, p. 151).

Overall, Köhler's studies did not provide much support for the proposal that chimpanzees share features of "folk physics" with humans, Povinelli notes. Nonetheless, on the basis that Köhler's studies provided ambiguous findings, and the more recent observations of wild chimpanzees using tools in diverse ways such as cracking nuts using stones, and fishing for termites using sticks (see Sanz et al., 2013, for several examples of such behaviors in wild chimpanzees documented since the 1960s), Povinelli suggests that tool use can offer "a window into folk physics" $(2000$, p. 73$)$ in chimpanzees. Povinelli (2000) states that "at the very least, most researchers would be willing to conclude that, given the same form and complexity of any given instance of tool use, the understanding of humans and chimpanzees are probably similar" (p. 83) and that chimpanzees hold "everyday folk notions of weight, force, gravity, shape, and so on" (p. 77). Whether chimpanzees hold these notions, and if they use them to appreciate causal relations of one object acting on another, is what he sought to examine experimentally.

\section{The Folk Physics for Apes Project: Objective, Methods, Findings}

Developmental psychologists have studied how infants and young children use physical events (such as the temporal ordering of objects' movements) to reason about cause and effect, and the variety of rules they use. Povinelli (2000, p. 97) refers particularly to Leslie et al.'s (1994) proposal that human infants possess an intrinsic (potentially unconscious) cognitive 'module' for tracking objects' energy distributions and their movement. This module converts visual stimulation into descriptions of energy distributions, leading to immediate expectations of outcomes. In adults (but not infants), the descriptions are further processed by higher-order (conscious) cognitive systems, with which we produce (conscious) causal attributions. According to Povinelli, this model suggests that humans and chimpanzees could share expectations about events in the physical world due to similar visual systems and statistical learning capacities.

Two-year-old toddlers start to use simple hand tools, such as a hook or a straight stick, in diverse ways, and they select hand tools based on features (such as length or rigidity) relevant to the task at hand (Brown, 1990). Povinelli interprets these findings as indicating that children attend to the causal relations between the tool and a target object by two years of age. Provocative results from work with capuchin monkeys and chimpanzees by Visalberghi and colleagues (Limongelli et al., 1995; Visalberghi \& Limongelli, 1994; Visalberghi \& Trinca, 1989) using a variation of an experimental tool-using task given to children by others suggested that capuchin monkeys did not attend to causal relations, but chimpanzees might have. Inspired by this effort, Povinelli and his colleagues devised a series of clever experiments, loosely linked to forms of tool use seen in wild chimpanzees, to test chimpanzees' comprehension of problems they could solve using simple hand tools (sticks).

The general experimental set-up involved training the chimpanzees to do a simple task (such as using a straight stick as a probe), then presenting variations of the task where they could choose a tool, or use a tool in different ways. For example, the first task Povinelli presented was a "trap-tube problem," built on Visalberghi and Limongelli's (1994) method. The chimpanzees were given a straight stick and initially presented with a clear horizontal tube, baited with a small piece of food. After they mastered 
using the stick to push out the food, the horizontal tube was altered to contain a T-junction in the center of the tube, which could be positioned on the bottom (serving as a trap) or top (not serving as a trap), and the stick was presented in different locations. For example, in Experiment 1D, there were three independent variables: the position of the stick (inserted in one end, placed near one end, or placed at the center of the tube), the position of the food relative to the T-junction (near one end or the other end) and the position of the T-junction (on the lower half of the tube, where it would catch the food, or on the top of the tube, where it did not affect the movement of the food). Figure 1 illustrates these conditions.

\section{Figure 1}

The 'Trap-Tube' Task (Povinelli, 2000, Experiment 1D)


Note. The location of the food, the stick, and the T-Junction in the tube varied across trials. Drawn after Povinelli (2000), Table 4.2.

Povinelli set out the predictions for these studies in terms of alternative models of reasoning. The High-level model was that chimpanzees reasoned about the causal structure of the task. The Low-level model was that chimpanzees used a procedural rule (such as insert the stick on the far side of the tube from the food, which would always lead to success), perceptual similarity, or some other alternative strategy, but not causal reasoning to guide their actions. For example, in the case of the trap-tube experiments, the High-level model predicted that chimpanzees would attend to the position of the stick in relation to the food when the T-junction was in the lower half of the tube (where it functioned as a trap), 
moving the stick as needed so that the food would not fall into the trap when pushed, but that they would ignore the position of the T-junction when it was on the top of the tube, facing upward. The behavior of the one chimpanzee tested with the conditions shown in Figure 1 did not support either of these models. The chimpanzee inserted the stick into the side opposite the food on all 15 tool-biased trials and all 16 tool-neutral trials. When the stick was already inserted into the tube, regardless of which side it was inserted into, she pushed it, rather than moving it to the opposite side of the tube before pushing it when it was originally inserted on the same side as the food. This mixed outcome was typical for the series of experiments reported in FPA: while it was clear that the High-level model's predictions were mainly not supported, neither were the predictions of the other models uniformly supported.

In the concluding chapter, Povinelli suggests that chimpanzees understand the physical world based on "observable phenomena" - that is, direct experience-because chimpanzees do not form concepts about entities and phenomena that do not have "perceptually-based exemplars" (2000, p. 298). Chimpanzees do not ascribe "causal concepts to events that consistently co-vary with each other" (2000, p. 299). In other words, chimpanzees cannot appreciate 'causality' as distinct from the specific actions and events they experience. Povinelli's concluding statement is that the empirical generalizations that guide the actions of chimpanzees "are derived from surface features of the problem which do not explicitly incorporate an entire class of concepts that humans have about causation..." (2000, p. 302303). Povinelli also acknowledged that chimpanzees "depend upon things that can be directly perceived..." (2000, p. 307). In sum, Povinelli concluded that, despite their spontaneous use of tools in natural settings and many other sophisticated actions with objects, chimpanzees do not reason about causal relations as do humans. This conclusion was useful to the field because it prompted people to question what other explanations could fit the data better and thus to consider alternative theories.

\section{Epistemological Alternative}

Direct realism, and its philosophical close cousin, Pragmatism, (Dreyfus \& Taylor, 2015; Frankel, 1996; Husserl, 2012; Popper, 2013; Putnam, 1983) offers an alternative epistemological framework to explore the questions that prompted Povinelli's grand project. Reed (1996), in a book entitled "Encountering the World," offers an accessible entrée to this philosophical school written expressly for psychologists, and we draw on his presentation to introduce Direct realism here.

Direct realist psychologists (at least, those sharing the views of James J. Gibson and Eleanor J. Gibson; see below) understand perception as direct, knowledge as experience, and cognition as the process by which the active individual maintains direct contact and thus ongoing commerce with the world (see Smythies \& French, 2018, for a recent treatment of the differences between Direct and Indirect realism in psychology). The first principle (Direct perception) most differentiates Direct realism from other forms of realism. Direct perception occurs by detection of patterns in ambient energy arrays that specify environmental properties. For example, patterns of reflected light specify surfaces and movement (of external features, and of the self). Animals perceive patterns of energy that are relevant to their goals and movements via their evolved perceptual systems (e.g., echolocation by bats and whales, fine visual discrimination of prey's movement by raptors, and tactile detection of vibration by spiders. Thus, there is no separation between the senses and perception. Presaging the Gibsons, Direct realism echoes in the work of eminent psychologists of the early $20^{\text {th }}$ century, such as William James $(1890,1912)$ and John Dewey (1910). For example, Louis Menand (1997, p. 218) paraphrases Dewey: "Knowing and doing are indivisible aspects of the same process, which is the business of adaptation."

At the time Povinelli conceived the FPA project (around 1990), Realism in experimental psychology was most evident in Ecological psychology, as founded by James J. Gibson $(1966,1979)$ in the field of perception and by Eleanor J. Gibson $(1969,1991)$ in the field of developmental psychology. Ecological psychology posits (1) that action and perception are continuous and fully integrated, (2) that affordances (the possibilities for action that the environment allows for an organism) are the entities of perception, and (3) that the organism-environment system is the proper unit of analysis. The theory emphasizes perceptual learning as an essential source of behavioral change. The Gibsons' theory is now 
well known by the two names of Ecological psychology and Perception/Action theory, which for our purposes in this essay are synonymous. We will use the term Ecological psychology.

Ecological psychology specifies that an animal knows the world in terms of affordances available to it, and actively seeks information about affordances to guide action (Gibson, 1966, 1979). Information can be categorized (for empirical examination) as exterospecific (a fact of the environment), and propriospecific (how an animal encounters the environment). Perception is simultaneously of both exterospecific and propriospecific information - in other words, of self in the environment. Animals are aware of their encounters with the world to the extent that "propriospecific information is available and picked up by them" (Reed, 1996, p. 49-50). Perception is prospective in that it guides action in the (immediate) future. Note that the awareness of affordances in the ecological approach is not tantamount to conscious self-awareness or reflective awareness (of cause and effect, for example). According to Reed (1996, p. 67), "awareness is not an internal state of the mind or brain, but an ecological and functional state of an animal making its way through the environment."

Lockman cogently applied the ecological approach to studying children's developing skills at using handheld objects as tools and perceiving tooling ${ }^{1}$ affordances (Kahrs \& Lockman, 2014b). He pointed out that tooling may be a more continuous developmental achievement for humans than had been previously believed (Lockman, 2000), and subsequent studies have confirmed overwhelmingly, that tooling develops gradually from infants' existing manual behaviors (Kahrs et al., 2012, 2013, 2014; Kahrs \& Lockman, 2014a; Lockman, 2008). Esther Thelen and colleagues arrived at parallel insights concerning the development of reaching in human infants (Thelen et al., 1996, 2001) and others have reached the same conclusion for the development of bimanual coordination in toddlers (Brakke \& Pacheco, 2019). Ecological psychology and other dynamical systems approaches continue to be used concurrently, often in the same work, as in Smith and Thelen (2003). Other domains of psychology where Ecological psychology has provided essential insights include perception of object affordances by muscular effort via dynamic touch, which is an essential component of tooling (e.g., Harrison et al., 2011; Mangalam et al., 2018; Wagman \& Carello, 2003). Direct realism underlies more empirical and theoretical works in psychology now than in the period when Povinelli conducted his studies, as evident in the flush of empirical and theoretical works conducted within or presenting an embodied view of cognition (see Shapiro, 2019, for overview). Several works investigating tooling in humans have adopted an Ecological stance or some variant of it (e.g., Baber, 2003; Baber et al., 2014; Biryukova et al., 2005, 2015; Bril et al., 2005, 2010; Smitsman et al., 2005) and Bril et al. (2009, 2012, 2015) have applied it to an analysis of chimpanzees using stones to crack nuts. In this new millennium, psychology appears to be in the midst of a shift in paradigm about the nature of knowledge and the function of the central nervous system (Anderson, 2014; Bassett \& Sporns, 2017; Cabe, 2018; Mangalam et al., 2020; Turvey \& Fonseca, 2014). No matter how that shift resolves, the Direct realist stance towards knowledge is particularly helpful to probing "what a chimpanzee understands about why tools produce the specific effects they do," as Povinelli (2000, p. 1) put it in the opening paragraph of the opening chapter of FPA.

Using a contemporary Direct realist stance, let us reconsider the design and findings of the studies reported in FPA. We will do so using an ecological, embodied theory of tooling (Fragaszy \& Mangalam, 2018). We deliberately chose the term 'tooling' as the name of our theory to privilege the actor and its action, rather than the object the actor uses. This theory addresses tooling at the level of the individual, as do theories of representational cognition, rather than (for example) as a cultural phenomenon. It is an embodied theory in the sense that no mediating representational processes are specified. Instead, the tooler acts to perceive affordances (opportunities for action), and perception of affordances guides action, in an ongoing cycle of action and perception. This theory applies equally well to tooling in all species. In the next section, we present an abbreviated précis of the embodied theory of tooling. In the final section, we apply this theory post hoc to the findings reported by Povinelli in FPA.

\footnotetext{
${ }^{1}$ We use "to tool" as a verb, meaning to act with a grasped object to achieve a mechanical goal (see full definition in the text) and "tooling" as a noun label for these actions.
} 


\section{Embodied Theory of Tooling}

The embodied theory of tooling that we propose integrates concepts from Ecological psychology and movement science. Ecological psychology gives us the concept of affordances, enabled by perception of surface layouts and use of exteroceptive and exproprioceptive information about external objects (including spatial relations among objects and orientation of body segments and the body as a unit to objects in the environment; Pagano et al., 1996), and movement science gives us concepts of degrees of freedom (DoFs) and coordination of movements. We briefly introduce these concepts next.

\section{Perceiving Tooling Affordances}

One of the central tenets of Gibson's embodied theory is that animals' perceptual systems are geared to pick up systematic regularities in the environment that specify opportunities for action ('affordances'), and their actions are geared to collecting such regularities (Gibson, 1966, 1979). Although the concept of affordances generates continuing discussion (Chemero, 2003; Cisek, 2007; Cisek \& Kalaska, 2010; Heft, 2003; Michaels, 2003; Stoffregen, 2003; Turvey, 1992), the consensus is that affordances emerge from the relation between a specific individual and a specific environment. For instance, a loamy, flat soil substrate affords tunneling to a mole, probing in search of worms to a robin, and walking to a fox (Figure 2). The same substrate affords different actions to different individuals. A fox could walk across loamy soil, but a heavier animal (e.g., horse) would sink to some depth if it stepped on the same surface. Affordances are not material properties of objects or surfaces, nor properties of the organism, but emerge from organism-environment relationships and change as these relationships change throughout development (Gibson, 2003; Gibson \& Pick, 2000).

\section{Figure 2}

Affordances: The Surface of a Loamy Soil Affords Tunneling to a Mole, Probing in Search of Prey to a Bird, and Walking to a Fox

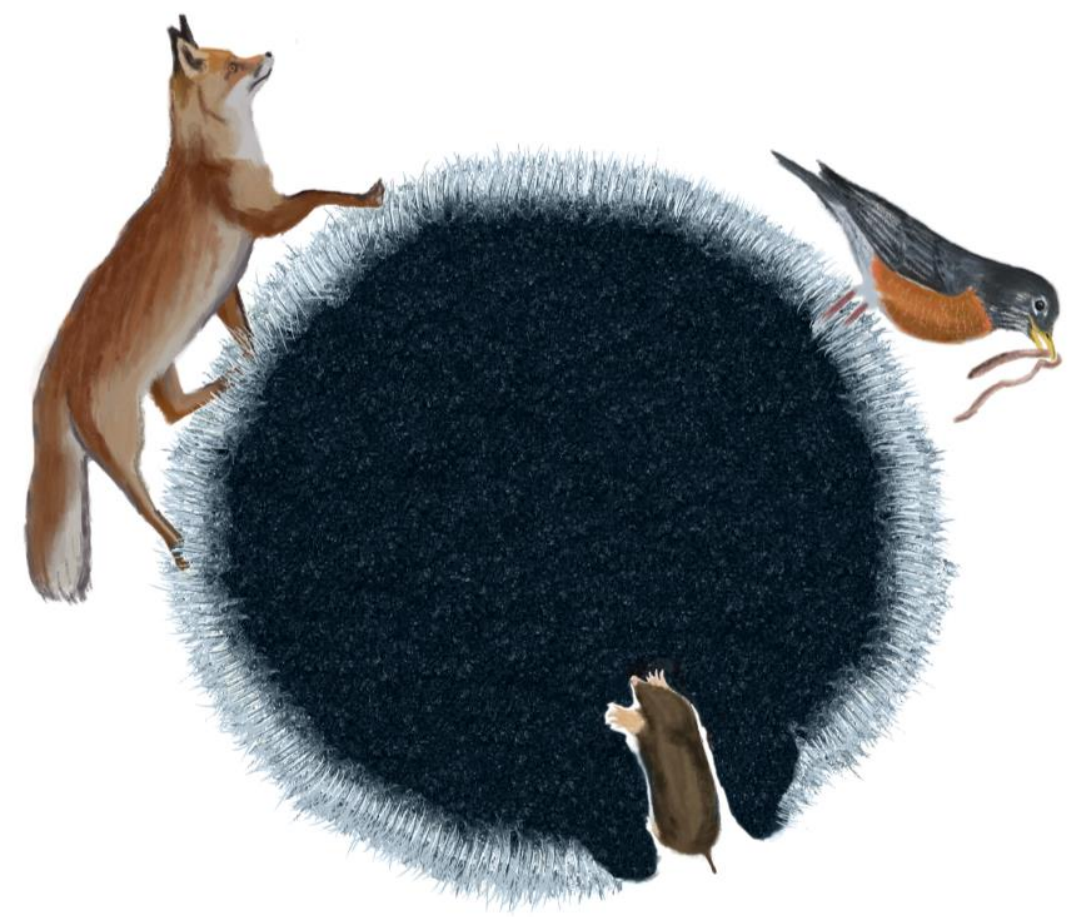

Drawing courtesy of Antonio J. Osuna-Mascaró. Reprinted from Fragaszy \& Mangalam (2018) Figure 1. 
Tooling affordances emerge from the suitability of objects and surfaces for the user to accomplish specific goals via specific actions. For example, a dowel's mass distribution along the long axis affects whether it affords hammering or poking (Wagman \& Carello, 2001). A dowel with its mass concentrated toward the distal end allows an efficient transfer of energy to a target and thus affords hammering. In contrast, a dowel with its mass concentrated toward the proximal end allows precise control over its distal tip and thus affords poking. A dowel affords neither of these things to a creature that cannot grasp and wield it from one end, nor if the targeted surface is liquid water, so that a dowel would simply penetrate the surface.

\section{Managing Spatial Relations Between a Grasped Object and the Target}

Tooling involves managing at least one, and often more than one, spatial relation between the grasped object and the target object or surface (or both). Animals employ two distinct spatial frames of reference to perceive and manipulate objects: egocentric and allocentric (Berthoz, 1991; Liben et al., 1981; Zaehle et al., 2007), and both are commonly used in tooling. In the egocentric frame of reference, animals perceive the location and features of an object relative to the self. In the allocentric frame of reference, animals perceive the location and features of an object relative to other objects in the environment. Note that the distinction between these two frames of reference is purely theoretical and does not imply representation. Perceptual information about location and features of an object relative to both the self and other objects can be generated by relative movement of the object, as specified in the visual array, for example. Young humans effectively manage egocentric relations in tooling before they master allocentric relations (for example, toddlers can brush their own hair before they can use a brush on a doll's hair; McCarty et al., 2001). Most experimental problems presented to nonhuman animals with the intent to evoke tooling involve producing and managing allocentric spatial relations (between the tool and some external target object or substrate), as in all the tool-using problems presented to chimpanzees by Povinelli in FPA.

Spatial relations between the tool and the target(s) can be produced concurrently or sequentially while tooling. For example, when using scissors to cut two pieces of paper placed one on top of the other, an individual manages two concurrent spatial relations - the pieces of paper relative to each other, and the scissors relative to the layer of papers. Each spatial relation can vary with respect to placement, orientation, and geometric alignment of the tool with the target object. For example, in the case of cutting paper with scissors, the intersection of the blades of the scissors should be placed at the point where cutting should begin; their long axis should be aligned with the intended line of cutting, and they should be oriented with the sharp edge of the blades perpendicular to the paper. Other positions of the scissors would prevent the blades from cutting the paper along the intended line or cutting at all. Finally, each spatial relation can vary in temporal dynamics, from static to dynamic. Holding two pieces of paper together with one hand involves managing a static spatial relation between the two pieces; cutting the layered pieces with scissors with the other hand involves managing a dynamic spatial relation between the scissors and the paper, as the blades move through the paper.

The spatial relations relevant to a given tooling episode can vary in all the dimensions noted above: frame of reference (egocentric or allocentric), number (and if two or more, their temporal order), specificity, and temporal dynamics. Various tooling episodes can be described using this uniform vocabulary.

\section{Coordinating and Controlling the DoFs of the Body-Plus-Object System}

An organism's body is a movement system, i.e., a set of elements forming a complex whole in interaction with the physical world in unity (Higgins, 1977). The vertebrate body is an open chain of rigid segments linked by joints. A rigid body can change its location in three-dimensional space through translations and rotations along the three perpendicular axes-lateral, normal, and longitudinal. The possibility of translational movement along an axis or rotational movement about an axis constitutes a 
degree of freedom (DoF). Joints of the human body have one to three DoFs. Controlling the movement of a grasped object involves the coordination of multiple DoFs of the body.

When tooling, the animal shifts the locus of control of movement in action from a part of the body that grasps an object to the part of the grasped object that contacts the target surface or object (e.g., the end of a stick, the edge of a stone or the blade of a knife), sometimes called the 'end-effector' (Arbib et al., 2009). Grasping an object transforms an animal's body into a body-plus-object system, which changes how DoFs of the body are organized, and adds at least one DoF to the system because the actor can move the object relative to the body (Mangalam, 2016; Mangalam \& Fragaszy, 2016; Valk et al., 2016). Consider grasping a screwdriver. The tooler can grip the top of the screwdriver with the fingertips and rotate it delicately by moving the thumb in the direction opposite to the other digits, or grasp the screwdriver firmly with fingers wrapped around the handle, to produce strong torque. Both of these grips redistribute the DoFs of the hand by coupling the hand and the screwdriver into a hand-plus-screwdriver system. The distal tip of the screwdriver becomes the end-effector, whether it is used as a lever, a poker, or to turn a screw.

\section{Definition of Tooling and Axioms}

We have combined concepts of affordances, perception and management of spatial relations, and coordination of movement into an embodied theory of tooling. To explain this theory, we define tooling: "Tooling is deliberately producing a mechanical effect upon a target object/surface by first grasping an object, thus transforming the body into the body-plus-object system, and then using the body-plus-object system to manage (at least one) spatial relation(s) between a grasped object and a target object/surface, creating a mechanical interface between the two. A bout of tooling begins when the tooler acts to establish the first spatial relation in the tooling sequence and ends after the last spatial relation in the sequence is established. For example, in hammering a nail, tooling begins when the tooler places the nail against the board, the bout continues while the tooler strikes the nail with the hammer, and ends when the tooler stops striking the nail and switches to some other activity." (Fragaszy \& Mangalam, 2018, p. 194). A tooling action is performed to achieve a specific mechanical effect on the target object or surface (e.g., to move an object across a surface, to penetrate a surface, to lift an object) - a 'goal.' This definition is species-neutral.

The following five axioms flesh out the embodied theory of tooling.

- An individual perceives the potential of producing a mechanical effect upon a target object/surface with a grasped object by perceiving affordances incorporating actions with objects.

- A grasped object transforms an individual's body into a body-plus-object system, reducing or redistributing the existing DoFs, and adding at least one new DoF.

- An individual creates a mechanical interface with a target by establishing (at least one) spatial relation(s) between the grasped object and the target.

- Through interrelated processes, an individual learns to:

- Perceive affordances incorporating actions with objects to produce a mechanical effect upon a target object/surface.

- Manage the spatial relations between the grasped object and the target object/surface to create a mechanical interface between the two.

- Coordinate and control the body-plus-object system to produce specific mechanical effects on the target object/surface.

This set of axioms, in combination with the definition of tooling given above, allows us to predict the likelihood of tooling to achieve specific goals appearing in diverse species and circumstances and the 
form that it would take. Explaining how the theory does this is beyond the scope of this article. We refer interested readers to Fragaszy and Mangalam (2018) for a fuller treatment.

\section{Solving Mechanical Problems by Tooling}

For a causal theory of tooling, solving a problem by tooling depends upon having an adequate representation of the problem and its solution. These features are not specific to the individual; they are mostly abstract. In contrast, in the embodied theory of tooling, a 'problem' is described in terms of the individual's abilities (strength, functional dexterity of the hands, length of the limb, visual acuity, visual depth perception, etc.), the constraints imposed by the task (e.g., to pull in an object that is out of reach), and the setting in which the task is encountered (in other words, the body-task-environment system). For example, to pull in an object out of reach, the setting includes the materials available to use to pull, the nature of the surfaces the object will cross, the shape, mass, solidity or other relevant properties of the object to be pulled, the space available to move the body, the presence of competitors, the time available to complete the action, and so on. Solving a problem by tooling depends upon the user's perception of affordance(s) for that individual to act with a given object to produce the intended mechanical effect on the target (i.e., to achieve their intended goal). Individuals will adopt solutions and develop the expertise to solve a given problem with a given tool object in accord with their characteristics and experience, as these govern the affordances they perceive and their effectiveness at achieving them by coordinating movements of the body-plus-object system. Their solutions will reflect the constraints of their own bodies (i.e., strength or dexterity), the demands of the task (e.g., to push food out of a tube using a stick), and the constraints of the environment (e.g., the length and diameter of the tube, Newell, 1986; Newell \& Jordan, 2007).

The constraint-led perspective outlined above is widely applied for studying the coordination and control of human movement (e.g., Al-abood et al., 2001) and the acquisition of skill by humans (e.g., Button et al., 2008). We have applied it to study the coordination and control of movements of the bodyplus-object system in capuchin monkeys (Mangalam et al., 2017; Mangalam \& Fragaszy, 2016), and Bril and colleagues have applied it to humans and chimpanzees (Bril et al., 2005, 2009, 2010, 2012, 2015).

Figure 3

Illustration of a Chimpanzee Fishing for Termites with a Plant Stem
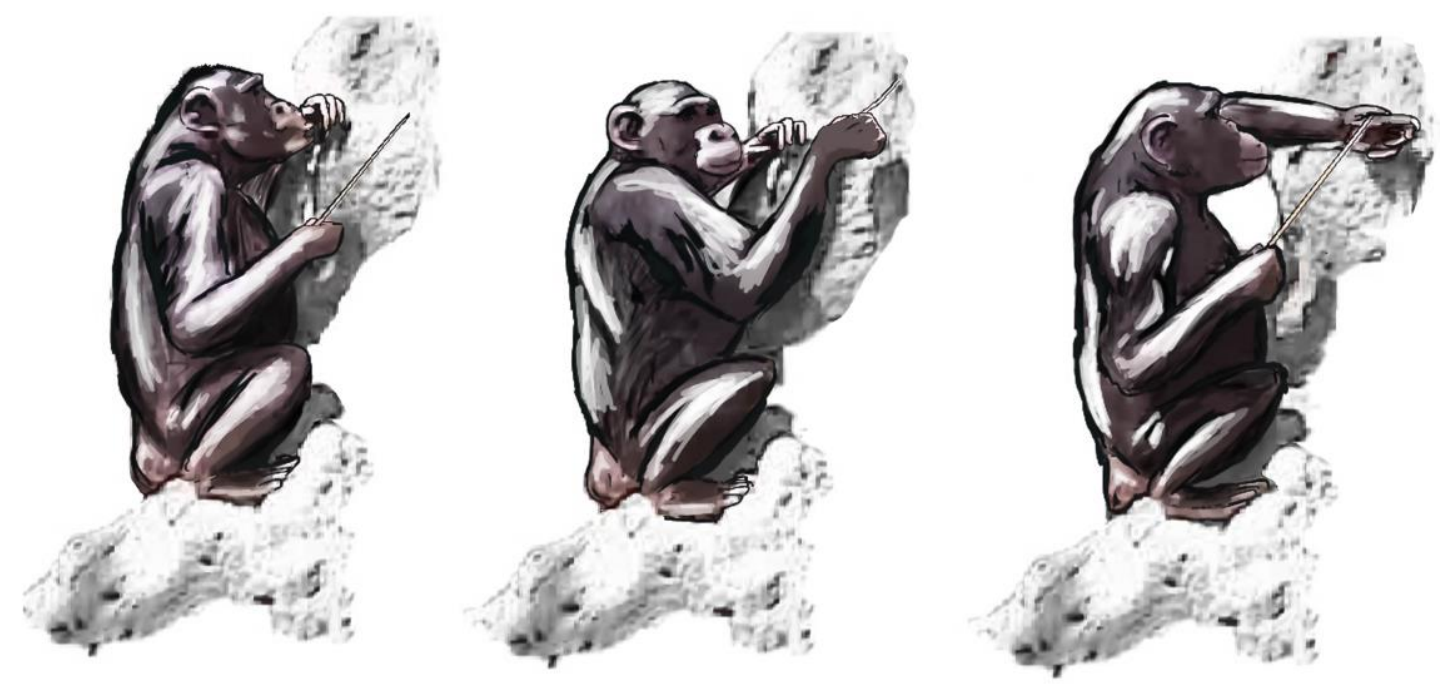

Drawing courtesy of Antonio J. Osuna-Mascaró. 
In summary, the embodied theory of tooling provides a useful direction for the development of ethological studies of tooling, as it provides a principled basis for specifying relevant features of the environment and task for individuals with varying morphologies, skills, and experience. Figure 3 provides an illustration of a well-known tooling activity of chimpanzees: fishing for termites using a plant probe. We can identify several task, environmental, and individual constraints in this activity. Task constraints might include force, torque, and spatial requirements to move the probe to a location and in such a way that the termites cling to it and can be retrieved. Environmental constraints might include weather, the friability of the termite mound, and the depth of the tunnel that must be probed. Individual constraints might include body mass, limb length, manual dexterity, range of motion of the limbs, sensibility to the movements of the probe, and motivation. Achieving the goal requires the actor to identify and collect a probe with appropriate affordances for insertion for the setting, actor, and task constraints. Then the actor must produce one allocentric spatial relation with the long axis of the probe oriented more or less perpendicularly to the wall of the nest and centered on the opening in the nest. To do this requires controlling the probe (which alters the body system so that it becomes the body-plus-object system as the chimpanzee wields the probe).

\section{Post hoc Application of the Embodied Theory of Tooling to Povinelli's Findings on Chimpanzees}

In this section, we consider Povinelli's findings on chimpanzees in terms of their perception of tooling affordances, managing spatial relations, and coordinating and controlling the DoFs of the bodyplus-object system. We focus on some of those aspects of chimpanzees' behavior that startled Povinelli but that are readily predicted by the embodied theory of tooling.

\section{Perceiving Tooling Affordances}

Povinelli reported in Chapter 5 of FPA the findings of experiments in which chimpanzees were presented with a series of 'trap-table' problems that built upon the trap-tube problem described in the previous chapter. In this problem, two rakes were presented side by side on a table, separated by a central divider. A piece of food was presented in front of each rake. The horizontal surface of one side of the table contained a gap in front of the food, so that if the rake on that side was pulled, the food would fall through the gap (into the "trap") and the chimpanzee could not retrieve it. The chimpanzees could choose either rake. In these studies, the chimpanzees did not reliably choose the rake that would afford retrieving the food and did not reliably avoid choosing a rake that would not afford retrieving the food. Note that the spatial relation between the food item and the surface of the table (or a gap in that surface) is allocentric with respect to the chimpanzee. Povinelli concluded that chimpanzees did not anticipate, before experience with the apparatus, that food would fall out of reach as it moved across the table when a gap was present. Sight of the experimental arrangement of tools, food, and the table surface was insufficient to inform their action. Moreover, Povinelli and colleagues specifically removed proprioceptive cues about the solidity of the surface that could be obtained when moving the rake across the surface after the first subject was 'startled' when the head of a rake fell into the gap. Following this event, they made the rake wider than the gap, so that the subjects did not 'feel' the gap as the rake moved across it (FPA, p. 137). To the extent that chimpanzees detect surface affordances through touch and proprioception, the absence of an opportunity to explore the objects and surfaces through touch would degrade the chimpanzees' perception of these surfaces. Of course, this is a post-hoc interpretation. The embodied theory of tooling predicts that chimpanzees would have similar problems in any judgment they should make about allocentric object/surface affordances (such as gaps in a surface that an object is moved across) using vision alone before having direct proprioceptive experience acting with the relevant components. Prospective studies can test the prediction. 


\section{Managing Spatial Relations Between a Grasped Object and the Target}

Some of the more striking findings in Povinelli's book came from the studies in which chimpanzees were offered sticks configured into different shapes to insert into an aperture to dislodge a piece of food (Chapter 8 of FPA). In this case, the chimpanzees were encouraged to handle the objects before the test trials and were allowed to manipulate the two sticks for the duration of each two-minute trial. After they were proficient at inserting a straight stick into the aperture to dislodge the food, they were given test trials with two sticks. In the first series of experiments, the sets of sticks were configured either with projecting ends (longer on one end and shorter on the other) or with no projections (Figure 4). In this situation, the chimpanzees typically spent more time handling sticks that had a projecting end than ones that did not, and they grasped the sticks with a projecting end in the manner that was most comfortable for them (i.e., they grasped the longer end). While holding this end, they could not easily dislodge the food because the other end was too short. In two subsequent experiments, the experimental sticks were altered to evaluate the alternative hypotheses that chimpanzees selected and grasped sticks in accord with the affordance of the sticks for grasping, or that they attended to the relation between the shape of one end of the stick and the aperture.

\section{Figure 4}

Sticks that Povinelli (2000, Experiment 11) Presented to Chimpanzees to Insert Through a Circular Aperture to Push a Piece of Food within their Reach.

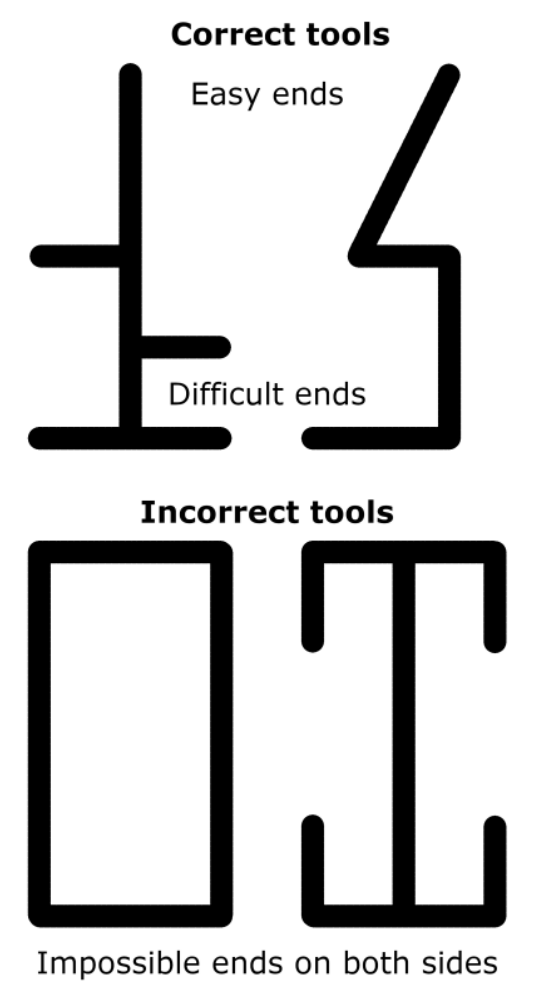

Drawn after Povinelli (2000) Figure 8.2.

The results of all these experiments indicated that the chimpanzees first grasped objects most comfortably, but eventually learned to reposition the object they grasped until, following repeated attempts, they inserted one end into the aperture. Povinelli writes, "they seemed to 'recognize' this perceptual configuration [when the correct ends passed in front of the hole] and then acted ... by pushing the tool toward the aperture." (2000, p. 205). However, they revealed no appreciation of the (allocentric) 
relation between the shape of the stick and its affordance for insertion into the aperture. Chimpanzees further demonstrated insensitivity to allocentric spatial relations present in many variants of problems that involved detection of a physical connection between a goal object and a supporting object (rope, hook, touching-stick, and cloth; Chapter 9), just as they had in the trap-table problems described earlier in this essay. In subsequent studies, chimpanzees again demonstrated limited perception of allocentric spatial relations when they attempted to insert three-dimensional objects of various shapes into matching cutouts (Fragaszy et al., 2011; la Cour et al., 2014). They managed to align the objects to the cut-outs by repeatedly sliding them across the surface in the vicinity of the cut-out, with minimal attention to the orientation of the axes of the object to the axes of the cut-out.

The chimpanzees' behavior with the variably shaped sticks may seem at odds with the most widespread form of tooling seen in wild chimpanzees, fishing for termites by inserting plant probes into holes in termite nests (e.g., Sanz et al., 2009). However, inserting a linear probe into a circular aperture involves bringing a single point to a single point - a more straightforward spatial relation than aligning lines or planes, as required to handle the stick correctly in the "shaped stick" problems presented by Povinelli and later by Fragaszy et al. (2011) and la Cour et al. (2014).

\section{Coordinating and Controlling the DoFs of the Body-Plus-Object System}

Recall that tooling requires management through movement of the body-plus-object system that is embedded in the environment. However, controlling the body-plus-object system was not explored in Povinelli's studies, as the reported variables related to performance concerned choice, duration and completion rather than movement. As the tasks added one DoF with the tool object and relied on familiar movements, such as pulling a rigid rake toward themselves (pulling tasks) or moving a rigid stick toward an aperture (probing tasks), controlling altered DoFs through coordinated movement was only mildly challenging in these tasks. Other forms of tooling that chimpanzees perform, such as delicately handling probes during fishing for termites, or handling nuts together with stones while cracking the nuts, are likely to be more revealing about chimpanzees' movement coordination when using an object as a tool. For example, Bril et al. (2009) showed that captive chimpanzees opening macadamia nuts using a stone hammer and anvil coordinated their movement to adjust the amplitude and velocity of their strikes in a manner that optimized the energetic output of their strikes to crack the nut.

\section{Conclusion}

Philosophers-Aristotle to Heidegger to those in the twenty-first century-have sought to understand humans' engagement with tools (Preston, 2012). The fascination extends to other species, in part because of humans' natural tendency to regard tooling as an indication of the exceptional quality of humans' technical intelligence and to attribute something like that quality of intelligence to other species when they are seen tooling. Povinelli's project presented in FPA reflected that natural tendency. The discrepancy between his predictions, grounded in the indirect realism of representational cognitive theory, and his findings prompted us to consider the findings from the different vantage point of Ecological psychology. We hope that this essay will prompt others to consider the merits of the Ecological approach or other alternative approaches (e.g., behavior-analytic approach; Machado \& Silva, 2003) to understand how individuals (nonhumans and humans) solve mechanical problems like those presented in FPA.

\section{References}

Al-abood, S. A., Davids, K., \& Bennett, S. J. (2001). Specificity of task constraints and effects of visual demonstrations and verbal instructions in directing learners' search during skill acquisition. Journal of Motor Behavior, 33(3), 295-305. https://doi.org/10.1080/00222890109601915

Anderson, M. L. (2014). After phrenology: Neural reuse and the interactive brain. MIT Press. 
Arbib, M. A., Bonaiuto, J. B., Jacobs, S., \& Frey, S. H. (2009). Tool use and the distalization of the end-effector. Psychological Research, 73(4), 441-462. https://doi.org/10.1007/s00426-009-0242-2

Baber, C. (2003). Cognition and tool use: Forms of engagement in human and animal use of tools. CRC Press.

Baber, C., Cengiz, T., \& Parekh, M. (2014). Tool use as distributed cognition: How tools help, hinder and define manual skill. Frontiers in psychology, 5(116). https://doi.org/10.3389/fpsyg.2014.00116

Bassett, D. S., \& Sporns, O. (2017). Network neuroscience. Nature Neuroscience, 20(3), 353-364. https://doi.org/10.1038/nn.4502

Bennett, M. R., \& Hacker, P. M. S. (2003). Philosophical foundations of neuroscience. Wiley-Blackwell.

Berkeley, G. (1988). Principles of human knowledge and three dialogues between Hylas and Philonous. Penguin Random House.

Berthoz, A. (1991). Reference frames for the perception and control of movement. In J. Paillard (Ed.), Brain and space (pp. 81-111). Oxford University Press.

Biryukova, E. V, Bril, B., Dietrich, G., Roby-Brami, A., Kulikov, M. A., \& Molchanov, P. E. (2005). The organization of arm kinematic synergies: The case of stone-bead knapping in Khambhat. In V. Roux \& B. Bril (Eds.), Stone knapping: The necessary conditions for a uniquely hominid behaviour (pp. 73-89). McDonald Institute for Archaeological Research.

Biryukova, E. V, Bril, B., Frolov, A. A., \& Koulikov, M. A. (2015). Movement kinematics as an index of the level of motor skill: The case of Indian craftsmen stone knapping. Motor Control, 19(1), 34-59. https://doi.org/10.1123/mc.2013-0042

Brakke, K., \& Pacheco, M. M. (2019). The development of bimanual coordination across toddlerhood. Monographs of the Society for Research in Child Development, 84(2), 7-147. https://doi.org/10.1111/mono.12405

Bril, B., Dietrich, G., Foucart, J., Fuwa, K., \& Hirata, S. (2009). Tool use as a way to assess cognition: How do captive chimpanzees handle the weight of the hammer when cracking a nut? Animal Cognition, 12(2), 217235. https://doi.org/10.1007/s10071-008-0184-x

Bril, B., Parry, R., \& Dietrich, G. (2015). How similar are nut-cracking and stone-flaking? A functional approach to percussive technology. Philosophical Transactions of the Royal Society of London. Series B, Biological Sciences, 370(1682), 20140355. https://doi.org/10.1098/rstb.2014.0355

Bril, B., Rein, R., Nonaka, T., Wenban-Smith, F., \& Dietrich, G. (2010). The role of expertise in tool use: Skill differences in functional action adaptations to task constraints. Journal of Experimental Psychology. Human Perception and Performance, 36(4), 825-839. https://doi.org/10.1037/a0018171

Bril, B., Roux, V., \& Dietrich, G. (2005). Stone knapping: Khambat (India), a unique opportunity? In V. Roux \& B. Bril (Eds.), Stone knapping: The necessary conditions for a uniquely hominin behaviour (pp. 53-71). McDonald Institute for Archaeological Research.

Bril, B., Smaers, J., Steele, J., Rein, R., Nonaka, T., Dietrich, G., Biryukova, E., Hirata, S., \& Roux, V. (2012). Functional mastery of percussive technology in nut-cracking and stone-flaking actions: Experimental comparison and implications for the evolution of the human brain. Philosophical Transactions of the Royal Society B: Biological Sciences, 367(1585), 59-74. https://doi.org/10.1098/rstb.2011.0147

Brown, A. L. (1990). Domain-specific principles affect learning and transfer in children. Cognitive Science, 14(1), 107-133. https://doi.org/10.1207/s15516709cog1401_6

Button, C., Davids, K., \& Bennett, S. (2008). Dynamics of skill acquisition: A constraints-led approach. Human Kinetics.

Cabe, P. A. (2018). All perception engages the tensegrity-based haptic medium. Ecological Psychology, 31(1), 113. https://doi.org/10.1080/10407413.2018.1526037

Chemero, A. (2003). An outline of a theory of affordances. Ecological Psychology, 15(2), 181-195. https://doi.org/10.1207/S15326969ECO1502 5

Cisek, P. (2007). Cortical mechanisms of action selection: The affordance competition hypothesis. Philosophical Transactions of the Royal Society B: Biological Sciences, 362(1485), 1585-1599. https://doi.org/10.1098/rstb.2007.2054

Cisek, P., \& Kalaska, J. F. (2010). Neural mechanisms for interacting with a world full of action choices. Annual Review of Neuroscience, 33(1), 269-298. https://doi.org/10.1146/annurev.neuro.051508.135409

Davidson, D. (2001). Essays on actions and events: Philosphical essays, Volume 1. Oxford University Press.

Dennett, D. C., \& Kinsbourne, M. (1992). Escape from the Cartesian theater. Behavioral and Brain Sciences, 15(2), 234-247. https://doi.org/10.1017/S0140525X00068527

Descartes, R. (1989). Passions of the soul. Hackett Publishing.

Dewey, J. (1910). How we think. Dover.

Dreyfus, H., \& Taylor, C. (2015). Retrieving realism. Harvard University Press. 
Fodor, J. A. (1974). Special sciences (or: The disunity of science as a working hypothesis). Synthese, 28(2), 97-115. http://www.jstor.org/stable/20114958

Fragaszy, D. M., \& Mangalam, M. (2018). Tooling. Advances in the Study of Behavior, 50, 177-241. https://doi.org/10.1016/bs.asb.2018.01.001

Fragaszy, D. M., Stone, B. W., Scott, N. M., \& Menzel, C. (2011). How tufted capuchin monkeys (Cebus apella spp) and common chimpanzees (Pan troglodytes) align objects to surfaces: Insights into spatial reasoning and implications for tool use. American Journal of Primatology, 73(10), 1012-1030. https://doi.org/10.1002/ajp.20966

Frankel, B. (1996). Roots of realism. Routledge.

Gibson, E. J. (1969). Principles of perceptual learning and development. Appleton-Century-Crofts.

Gibson, E. J. (1991). An odyssey in learning and perception. MIT Press.

Gibson, E. J. (2003). The world is so full of a number of things: On specification and perceptual learning. Ecological Psychology, 15(4), 283-287. https://doi.org/10.1207/s15326969eco1504_3

Gibson, E. J., \& Pick, A. D. (2000). An ecological approach to perceptual learning and development. Oxford University Press.

Gibson, J. J. (1966). The senses considered as perceptual systems. Houghton Mifflin.

Gibson, J. J. (1979). The ecological approach to visual perception. Houghton Mifflin.

Harrison, S. J., Hajnal, A., Lopresti-Goodman, S., Isenhower, R. W., \& Kinsella-Shaw, J. M. (2011). Perceiving action-relevant properties of tools through dynamic touch: Effects of mass distribution, exploration style, and intention. Journal of Experimental Psychology: Human Perception and Performance, 37(1), 193-206. https://doi.org/10.1037/a0020407

Heft, H. (2003). Affordances, dynamic experience, and the challenge of reification. Ecological Psychology, 15(2), 149-180. https://doi.org/10.1207/S15326969ECO1502_4

Higgins, J. R. (1977). Human movement: An integrated approach. Mosby.

Hume, D. (1986). A treatise of human nature. Penguin Random House.

Husserl, E. (2012). Ideas: General introduction to pure phenomenology. Routledge.

James, W. (1890). The principles of psychology. Harvard University Press.

James, W. (1912). Essays in radical empiricism. Henry Holt.

Kahrs, B. A., Jung, W. P., \& Lockman, J. J. (2012). What is the role of infant banging in the development of tool use? Experimental Brain Research, 218(2), 315-320. https://doi.org/10.1007/s00221-012-3062-3

Kahrs, B. A., Jung, W. P., \& Lockman, J. J. (2013). Motor origins of tool use. Child Development, 84(3), 810-816. https://doi.org/10.1111/cdev.12000

Kahrs, B. A., Jung, W. P., \& Lockman, J. J. (2014). When does tool use become distinctively human? Hammering in young children. Child Development, 85(3), 1050-1061. https://doi.org/10.1111/cdev.12179

Kahrs, B. A., \& Lockman, J. J. (2014a). Building tool use from object manipulation: A perception-action perspective. Ecological Psychology, 26(1-2), 88-97. https://doi.org/10.1080/10407413.2014.874908

Kahrs, B. A., \& Lockman, J. J. (2014b). Tool using. Child Development Perspectives, 8(4), 231-236. https://doi.org/10.1111/cdep.12087

Köhler, W. (1927). The mentality of apes, $2^{\text {nd }}$ revised ed. Harcourt Brace. Translated by Ella Winters.

la Cour, L. T., Stone, B. W., Hopkins, W., Menzel, C., \& Fragaszy, D. M. (2014). What limits tool use in nonhuman primates? Insights from tufted capuchin monkeys (Sapajus spp.) and chimpanzees (Pan troglodytes) aligning three-dimensional objects to a surface. Animal Cognition, 17(1), 113-125. https://doi.org/10.1007/s10071-013-0643-X

Leslie, A. M., German, T. P., \& Happé, F. G. (1993). Even a theory-theory needs information processing: ToMM, an alternative theory-theory of the child's theory of mind. Behavioral and Brain Sciences, 16(1), 56-57. https://doi.org/DOI: 10.1017/S0140525X00028934

Liben, L. S., Patterson, A. H., \& Newcombe, N. (1981). Spatial representation and behavior across the life span. Academic Press.

Limongelli, L., Boysen, S. T., \& Visalberghi, E. (1995). Comprehension of cause-effect relations in a tool-using task by chimpanzees (Pan troglodytes). Journal of Comparative Psychology, 109(1), 18-26. https://doi.org/10.1037/0735-7036.109.1.18

Locke, J. (1998). An essay concerning human understanding. Penguin Random House.

Lockman, J. J. (2000). A perception-action perspective on tool use development. Child Development, 71(1), 137144. https://doi.org/10.1111/1467-8624.00127

Lockman, J. J. (2008). On tool use, perseveration and task dynamics. Infancy, 13(3), 279-283. https://doi.org/10.1080/15250000802004072 
Machado, A., \& Silva, F. J. (2003). You can lead an ape to a tool, but ...: A review of Povinelli's folk physics for apes: The chimpanzee's theory of how the world works. Journal of the Experimental Analysis of Behavior, 79(2), 267-286. https://doi.org/10.1901/jeab.2003.79-267

Mangalam, M. (2016). What makes a tool. In T. K. Shackelford, \& V. A. Weekes-Shackelford (Eds.), Encyclopedia of evolutionary psychological science (pp. 1-5). Springer. https://doi.org/10.1007/978-3-319-169996_3153-1

Mangalam, M., Chen, R., McHugh, T. R., Singh, T., \& Kelty-Stephen, D. G. (2020). Bodywide fluctuations support manual exploration: Fractal fluctuations in posture predict perception of heaviness and length via effortful touch by the hand. Human Movement Science, 69, 102543. https://doi.org/10.1016/j.humov.2019.102543

Mangalam, M., Conners, J. D., Fragaszy, D. M., \& Newell, K. M. (2018). Location of a grasped object's effector influences perception of the length of that object via dynamic touch. Experimental Brain Research, 236(7), 2107-2121. https://doi.org/10.1007/s00221-018-5287-2

Mangalam, M., \& Fragaszy, D. M. (2016). Transforming the body-only system into the body-plus-tool system. Animal Behaviour, 117, 115-122. https://doi.org/10.1016/j.anbehav.2016.04.016

Mangalam, M., Newell, K. M., Visalberghi, E., \& Fragaszy, D. M. (2017). Stone-tool use in wild monkeys: Implications for the study of the body-plus-tool system. Ecological Psychology, 29(4), 300-316. https://doi.org/10.1080/10407413.2017.1369852

McCarty, M. E., Clifton, R. K., \& Collard, R. R. (2001). The beginnings of tool use by infants and toddlers. Infancy, 2(2), 233-256. https://doi.org/10.1207/S15327078IN0202_8

Menand, L. (1997). Pragmatism. Penguin Random House.

Michaels, C. F. (2003). Affordances: Four points of debate. Ecological Psychology, 15(2), 135-148. https://doi.org/10.1207/S15326969ECO1502_3

Newell, K. M. (1986). Constraints on the development of coordination. In M. G. Wade \& H. T. Whiting (Eds.), Motor development in children: Aspects of coordination and control (pp. 341-360). Martinus Nijhoff.

Newell, K. M., \& Jordan, K. (2007). Task constraints and movement organization: A common language. In G. D. Broadhead \& W. E. Davis (Eds.), Ecological task analysis and movement (pp. 5-23). Human Kinetics.

Pagano, C. C., Carello, C. \& Turvey, M. T. (1996). Exteroception and exproprioception by dynamic touch are different functions of the inertia tensor. Perception \& Psychophysics, 58, 1191-1202. https://doi.org/10.3758/BF03207552

Popper, K. (2013). Realism and the aim of science: From the postscript to the logic of scientific discovery. Routledge.

Povinelli, D. J. (2000). Folk physics for apes: The chimpanzee's theory of how the world works. Oxford University Press.

Preston, B. (2012). A philosophy of material culture: Action, function, and mind. Routledge.

Putnam, H. (1983). Realism and reason: Philosophical papers, Vol. 3. Cambridge University Press.

Reed, E. S. (1996). Encountering the world: Toward an ecological psychology. Oxford University Press.

Sanz, C. M., Call, J., \& Boesch, C. (2013). Tool use in animals: Cognition and ecology. Cambridge University Press.

Sanz, C. M., Call, J., \& Morgan, D. (2009). Design complexity in termite-fishing tools of chimpanzees (Pan troglodytes). Biology Letters, 5(3), 293-296. https://doi.org/10.1098/rsbl.2008.0786

Shapiro, L. (2019). Embodied cognition. Routledge.

Smith, L. B., \& Thelen, E. (2003). Development as a dynamic system. Trends in Cognitive Sciences, 7(8), 343-348. https://doi.org/10.1016/S1364-6613(03)00156-6

Smitsman, A. W., Cox, R. F. A., \& Bongers, R. M. (2005). Action dynamics in tool use. In V. Roux \& B. Bril (Eds.), Stone knapping: The necessary conditions for a uniquely hominid behaviour (pp. 129-144). McDonald Institute for Archaeological Research.

Smythies, J. R., \& French, R. E. (2018). Direct versus indirect realism: A neurophilosophical debate on consciousness. Academic Press.

Stoffregen, T. A. (2003). Affordances as properties of the animal-environment system. Ecological Psychology, 15(2), 115-134. https://doi.org/10.1207/S15326969ECO1502_2

Thelen, E., Corbetta, D., \& Spencer, J. P. (1996). Development of reaching during the first year: Role of movement speed. Journal of Experimental Psychology: Human Perception and Performance, 22(5), 1059-1076. https://doi.org/10.1037/0096-1523.22.5.1059

Thelen, E., Schöner, G., Scheier, C., \& Smith, L. B. (2001). The dynamics of embodiment: A field theory of infant perseverative reaching. Behavioral and Brain Sciences, 24(1), 1-34. https://doi.org/10.1017/S0140525X01003910 
Turvey, M. T. (1992). Affordances and prospective control: An outline of the ontology. Ecological Psychology, 4(3), 173-187. https://doi.org/10.1207/s15326969eco0403_3

Turvey, M. T., \& Fonseca, S. T. (2014). The medium of haptic perception: A tensegrity hypothesis. Journal of Motor Behavior, 46(3), 143-187. https://doi.org/10.1080/00222895.2013.798252

Valk, T. A., Mouton, L. J., \& Bongers, R. M. (2016). Joint-angle coordination patterns ensure stabilization of a body-plus-tool system in point-to-point movements with a rod. Frontiers in Psychology, 7, 826. https://doi.org/10.3389/fpsyg.2016.00826

Visalberghi, E., \& Limongelli, L. (1994). Lack of comprehension of cause-effect relations in tool-using capuchin monkeys (Cebus apella). Journal of Comparative Psychology, 108(1), 15-22. https://doi.org/10.1037/0735$\underline{7036.108 .1 .15}$

Visalberghi, E., \& Trinca, L. (1989). Tool use in capuchin monkeys: Distinguishing between performing and understanding. Primates, 30(4), 511-521. https://doi.org/10.1007/BF02380877

Wagman, J. B., \& Carello, C. (2001). Affordances and inertial constraints on tool use. Ecological Psychology, 13(3), 173-195. https://doi.org/10.1207/S15326969ECO1303_1

Wagman, J. B., \& Carello, C. (2003). Haptically creating affordances: The user-tool interface. Journal of Experimental Psychology: Applied, 9(3), 175-186. https://doi.org/10.1037/1076-898X.9.3.175

Zaehle, T., Jordan, K., Wüstenberg, T., Baudewig, J., Dechent, P., \& Mast, F. W. (2007). The neural basis of the egocentric and allocentric spatial frame of reference. Brain Research, 1137, 92-103. https://doi.org/10.1016/j.brainres.2006.12.044 